\title{
Uso de tecnologías educativas en la enseñanza de la ciencia y la biología: tendencias de investigación de acuerdo con las revistas nacionales
}

\author{
Beatriz Grigio Bornia ${ }^{1}$ \\ biagrigio@hotmail.com \\ https://orcid.org/0000-0002-7860-4299 \\ Marcia Regina Royer ${ }^{1}$ \\ marciaroyer@yahoo.com.br \\ https://orcid.org/0000-0002-6369-9440 \\ ${ }^{1}$ Universidade Estadual do Paraná (UNESPAR, Brasil)
}

Recibido: 25/04/2020 Aceptado: 12/07/2020

\begin{abstract}
Resumen
El expresivo avance tecnológico manifestado en las últimas décadas ha generado cambios en el escenario educativo, principalmente después de la promulgación del decreto número 6.300, que prevé el Programa Nacional de Tecnología Educativa - ProInfo, en 2007. De esta manera, buscamos delimitar el escenario nacional actual de las implementaciones de la Tecnología de la información y la comunicación (TIC) en la enseñanza de las ciencias naturales a través de la encuesta bibliográfica de siete revistas con Qualis (CAPES) A1 y A2, en Docencia, entre 2007 y 2019, de las 550 publicaciones encontradas sobre este tema. Los criterios de evaluación fueron: número de publicaciones anuales por revista, número de publicaciones por año; nivel educativo; modalidades de enseñanza; disciplinas en las que se aplicaron las TIC; subáreas de biología; Enfoques temáticos y recursos tecnológicos utilizados. Si bien la adopción de tecnologías permite promover una educación accesible e interdisciplinaria y cautivar la autonomía de los estudiantes, su implementación requiere infraestructura, capacitación docente y recursos financieros, las adversidades que se presentan como desafíos importantes frente a las comunidades necesitadas y las desigualdades presentes en Brasil en la actualidad. Las investigaciones sobre inclusión se basaron principalmente en la sordera, sin expandirse a otras deficiencias, aunque el creciente énfasis en las tecnologías didácticas aplicadas a la Educación Ambiental ha mostrado resultados positivos.
\end{abstract}

Palabras clave: Ciencias; Educación; Tecnología.

\section{Uso de tecnologias educacionais no ensino de ciências e biologia: tendências de pesquisa de acordo com os periódicos nacionais}

\section{Resumo}

O avanço tecnológico expressivo manifestado nas últimas décadas gerou alterações no cenário educacional, principalmente após a promulgação do decreto $\mathrm{n}^{0} 6.300$, que dispõe sobre o Programa Nacional de Tecnologia Educacional - ProInfo, em 2007. Deste modo, buscamos delimitar o cenário nacional vigente das implementações da Tecnologia de Informação e Comunicação (TIC) no ensino de Ciências Naturais mediante o levantamento bibliográfico de sete periódicos com Qualis (CAPES) A1 e A2, em Ensino, entre 2007 e 2019, a partir das 550 publicações encontradas com esta temática. Os critérios de avaliação foram: quantidade de publicações anuais por revista, quantidade de publicações por ano; nível de ensino; modalidades de ensino; disciplinas em que as TIC foram aplicadas; subáreas 
da biologia; enfoques temáticos e recursos tecnológicos utilizados. Embora a adesão de tecnologias possibilite promover a educação acessível, interdisciplinar e cativando a autonomia do aluno, sua implantação necessita infraestrutura, formação docente e recursos financeiros, adversidades apresentadas como grandes desafios diante de comunidades carentes e desigualdades presentes no Brasil atualmente. As pesquisas tratando-se de inclusão pautaram-se principalmente na surdez, sem ampliação a outras deficiências, embora a crescente ênfase de tecnologias didáticas aplicadas à Educação Ambiental apresentou resultados positivos.

Palavras-chave: Ciências; Educação; Tecnologia.

\title{
Use of educational technologies in science and biology teaching: search trends in accordance with national journals
}

\begin{abstract}
The expressive technological advances manifested in the last decades generated changes in the educational scenario, mainly after the enactment of the decree no. 6,300, which provides for the National Educational Technology Program - ProInfo, in 2007. In this way, we seek to delimit the current national scenario of the implementations of the Information and Communication Technology (ICT) in the teaching of Natural Sciences through the bibliographical survey of seven journals with Qualis (CAPES) A1 and A2, in Teaching, between 2007 and 2019, from the 550 publications found on this theme. The evaluation criteria were: number of annual publications per magazine, number of publications per year; level of education; teaching modalities; disciplines in which ICTs were applied; sub-areas of biology; thematic approaches and technological resources used. Although the adoption of technologies makes it possible to promote accessible, interdisciplinary education and captivate student autonomy, its implementation requires infrastructure, teacher training and financial resources, adversities presented as major challenges in the face of needy communities and inequalities present in Brazil today. Researches on inclusion were mainly based on deafness, without expanding to other deficiencies, although the growing emphasis on didactic technologies applied to Environmental Education has shown positive results.
\end{abstract}

Keywords: Sciences; Education; Technology.

\section{Introdução}

O considerável avanço tecnológico presenciado desde o século XX gerou profundas mudanças de âmbito político, econômico, social e ambiental. Tais manifestações convergem diretamente ao ensino, uma vez que o aluno se depara com novos conceitos essenciais em sua formação cognitiva e cidadã. No entanto, o acesso a tais tecnologias, embora viabilize a concepção do saber, possibilita a aquisição de informações equivocadas pelos estudantes, se não orientados devidamente. Os professores, por sua vez, passam a desempenhar o papel de mediador do conhecimento em sala de aula, não cabendo-lhes mais a concepção de único detentor do saber no meio escolar, mas também contribuindo para a adesão das Tecnologias de Informação e Comunicação (TIC) como recursos didáticos. 
Inovações educacionais do início de 1970 manifestaram-se como um estopim para a alteração na concepção neutra e compartimentalizada do ensino de ciência na educação básica, com incentivo de órgãos governamentais. Deste modo, visando um ensino interdisciplinar, promotor do conhecimento crítico e contextualizado, origina-se o movimento Ciência, Tecnologia e Sociedade (CTS), com objetivo de promover a alfabetização científica e tecnológica dos estudantes.

Consoante ao debate vigente a respeito da inserção de metodologias contextualizadas, "a interdisciplinaridade é destacada em muitas pesquisas e revisões como necessária para as discussões CTS, estabelecendo um diálogo com outras disciplinas, entre elas a filosofia e a história da ciência" (Raad, Matos \& Coutinho, 2018, p. 6). Associada à alfabetização científica, a CTS articula-se, portanto, á concepções políticas, ambientais, éticas, sociais, históricas e tecnológicas em prol de capacitar o aluno para a resolução de problemas reais.

Atualmente, escolas desprovidas de redes digitais encontram-se excluídas ao acesso de informação variada disponível online, cuja praticidade e integração a bibliotecas virtuais, serviços digitais, bases de dados, portais educacionais e divulgação de eventos e congressos viabilizam a assimilação de conteúdo, disciplinas e troca de conhecimento com pessoas situadas em locais distintos. Neste sentido, Cruz et al., (2018, p. 100) mencionam que "com o advento de novas tecnologias, é necessária a atualização das práticas metodológicas de ensino, pois motivação e modernização minimizam a evasão escolar e o desinteresse por parte dos alunos".

Deste modo, a inserção da TIC compactua com propostas para as adversidades do século XXI, pautando-se na educação que envereda para o desenvolvimento cognitivo e crítico do aluno, somado as atividades universitárias voltadas para a pesquisa e formação cidadã que suscitam avanços tecnológicos em prol da sociedade.

Deste modo, Moreira (2018, p. 230) apontam que as tecnologias compreendem não somente computadores e internet, mas todos os sistemas e processos desenvolvidos pelo ser humano, como calculadoras, câmeras digitais, softwares, lunetas e microscópios.

Com a promulgação do decreto (Decreto 6.300, 2007), que dispõe sobre Programa Nacional de Tecnologia Educacional (ProInfo) e promove a utilização de recursos digitais na instituição escolar, simultaneamente atribuiu vantagens a educação relacionadas a acessibilidade, autonomia dos estudantes e experimentação virtual como elo entre teoria e 
prática. Com efeito, o uso de TIC em ciências naturais, deve ressaltar a infraestrutura, recursos financeiros e formação inicial e continuada constantemente atualizada em prol de sua implementação na prática docente de modo eficiente, culminando no incentivo à alfabetização cientifica, não pautando-se apenas em metodologias conservadoras que sobrecarreguem o estudante com conceitos memorizados que não lhe fazem sentido. De modo complementar, tal cenário compactua com a redução da evasão escolar, uma vez que integra interesse aos estudantes e assimilação dos saberes como consequências de concepções cotidianas do estudante.

Deste modo, averiguar os avanços e regressos na inserção de TIC na educação possibilita diagnosticar as lacunas e potencialidades deste programa em nosso país, quanto à infraestrutura, formação de professores, concepção dos estudantes, metodologias e disciplinas envolvidas. Com a adesão de novas tecnologias e seu gradual desenvolvimento, buscamos analisar, através de publicações em sete periódicos, a aplicação da TIC no ensino das Ciências Naturais e suas potencialidades.

\section{Metodologia}

Este trabalho consiste em uma revisão de literatura integrativa, caracterizado por extrair conclusões e hipóteses de publicações com o mesmo enfoque de pesquisa, visando relacionar os dados obtidos e gerar uma posterior discussão. Utilizamos procedimentos comumente empregados em pesquisas do tipo "estado da arte" para estimar as perspectivas vigentes da tecnologia no ensino de Ciências e Biologia. Logo, as pesquisas de levantamento bibliográfico:

[...] podem significar uma contribuição importante na constituição do campo teórico de uma área de conhecimento, pois procuram identificar os aportes significativos da construção da teoria e prática pedagógica, apontar as restrições sobre o campo em que se move a pesquisa, as suas lacunas de disseminação, identificar experiências inovadoras investigadas que apontem alternativas de solução para os problemas da prática e reconhecer as contribuições da pesquisa na constituição de propostas na área focalizada (Romanowski \& Ens, 2006, p. 39).

Neste contexto, realizamos a análise de artigos publicados em sete periódicos científicos brasileiros, de acesso online, avaliadas no quadriênio de 2013-2016 com Qualis A1 e A2, na área de ensino, pela Coordenação de Aperfeiçoamento de Pessoal de Nível Superior (CAPES) que é uma fundação vinculada ao Ministério da Educação e Cultura (MEC) que atua na expansão e consolidação da pós-graduação - mestrados e doutorados. A 
classificação de periódicos é realizada pelas áreas de avaliação e passa por processo anual de atualização.

Optamos por tais fontes pois acreditamos que tais revistas forneçam um bom indicativo do escopo da pesquisa em Tecnologia aplicada no ensino de Ciências e Biologia. Os periódicos científicos escolhidos compreendem: 1-Ciências \& Educação (A1), 2-Ensaio Pesquisa em Educação em Ciências (A1), 3-ARETÉ- Revista Amazônica de Ensino de Ciências (A2), 4-Revista Brasileira de Ensino de Ciência e Tecnologia (A2), 5-Investigações no Ensino de Ciências (A2), 6-RENCIMA- Revista de Ciências e Ensino de Matemática (A2) e 7-Revista Brasileira de Pesquisa em Educação em Ciências (A2). Para identificação destes sete periódicos os mesmos foram codificados pela letra $\mathrm{P}$ seguida de numeração arábica, sendo eles P1, P2, P3, P4, P5, P6 e P7, respectivamente.

O marco temporal inicial estimado para a análise dos artigos compreende 2007, visto que neste ano foi promulgado o Decreto $n^{0}$ 6.300/2007, que dispõe sobre o ProInfo, cujo objetivo volta-se ao levantamento de perspectivas nacionais e lacunas das dimensões do uso das TIC aplicadas no Ensino de Ciências Naturais no Brasil. O marco final foi dezembro de 2019, ano em que esta pesquisa foi realizada.

A princípio, executamos um levantamento bibliográfico quantitativo de publicações anuais por periódico com enfoque no uso de tecnologias educacionais no ensino de ciências e biologia, totalizando 550 artigos, dos quais 282 a leitura completa foi realizada e os demais restringimos a interpretação dos resumos. Para cumprir com maior eficácia o propósito do artigo, disponibilizamos o link https://unesparmy.sharepoint.com/:b:/g/personal/ppifor_ensino_unespar_edu_br/EbJiWKvg71NCmF20f6Y_g4BztHz-f0XoP9Isk3iICgN5A?e=2ngrF1 de uma página pública na internet constando uma tabela com as referências dos 550 artigos pesquisados (nome da revista, ano, título, autores, volume, número e periodicidade).

Os critérios de avaliação para os periódicos foram: quantidade de publicações anuais por periódico e número de artigos por ano pesquisado. Quanto a análise dos artigos, pontuamos: Nível de ensino; Modalidades de ensino; Disciplinas em que as TIC foram aplicadas; Subáreas da biologia; Enfoques Temáticos e Recursos tecnológicos utilizados.

No tópico "Quantidade de publicações anuais por periódico", buscamos destacar o número de artigos encontrados por ano, entre o recorte temporal de 2007 a 2019, de acordo com os critérios estabelecidos, independentemente da periodicidade da revista, embora este 
fator seja ressaltado posteriormente como um facilitador ou não da quantidade de pesquisas examinadas entre o recorte temporal de 2007 a 2019.

Em "Níveis de Ensino," averiguamos a quantidade de artigos publicados segundo a Lei de Diretrizes e Bases da Educação Nacional (LDB), descritas no Art. 21: “A educação escolar compõe-se de: I - educação básica, formada pela educação infantil, ensino fundamental e ensino médio; II - educação superior” (Decreto 6.300, 2007).

Não obstante, seguimos a organização da educação disposta na LDB (Decreto 6.300, 2007) para educação básica segundo o Art. $4^{\circ}$, inciso I, em “a) pré-escola; b) ensino fundamental; c) ensino médio" e ensino superior conforme o Art. 44, incisos II e III, tratando-se respectivamente da graduação e pós-graduação.

Quanto as "Modalidades de ensino", verificamos os seguintes tópicos: educação formal, educação não formal, educação informal, Educação de Jovens e Adultos (EJA), Educação à Distância (EAD), educação profissional e tecnológica e educação indígena.

Em "Disciplinas em que as TIC foram aplicadas", apuramos apenas as Ciências da Natureza: Ciências no Ensino Fundamental e Física, Química e Biologia, ao ensino médio e graduação. Visamos destacar as subáreas da Biologia, distribuindo-as em: botânica, zoologia, microbiologia e citologia, histologia, morfologia, anatomia e fisiologia humana, bioquímica, ecologia, genética, saúde, educação sexual, educação ambiental, evolução e paleontologia.

A análise dos "Enfoques temáticos" foi realizada segundo o Catálogo de teses e dissertações do CEDOC (Centro de Documentação em Ensino de Ciências) estipulado por Megid Neto (1998), contemplando Currículos e Programas, Formação de Professores, Conteúdo-Método, Recursos Didáticos, Formação de Conceitos, Características do Professor, Características do Aluno, Organização da Escola, Organização da Instituição/Programa de Ensino Não-Escolar, Políticas Públicas, História do Ensino de Ciências, História e Filosofia da Ciência e Inclusão. Vale destacar que, de acordo com os dados levantados, muitas pesquisas apresentaram mais de um enfoque temático.

Em “Recursos Didáticos", classificamos as tecnologias encontradas tangentes aos usos nas pesquisas analisadas, em: Software e simulações, fotografia, recursos audiovisuais, modelagem computacional, jogos digitais, hardware, Ambiente Virtual de Aprendizagem (AVA) e outros. 


\section{Resultados e Discussão}

Imbuídos pelo desejo de responder ao escopo desta pesquisa, apresentamos na tabela 1, a origem das 550 publicações selecionadas tratando-se do ensino de Ciências Naturais mediado por tecnologia, de acordo com os anos (2007 a 2019) e periódicos pesquisados (P1, P2, P3, P4, P5, P6 e P7).

Podemos notar na tabela 1 que o periódico com mais artigos sobre ao uso de tecnologias educacionais no ensino de ciências e biologia foi a Revista P1, de periodicidade quadrimestral, com 181 (32,91\%) artigos. Acreditamos que este porcentual elevado decorre de o escopo da revista voltar-se estritamente a tecnologia, bem como a diversidade de idiomas aceitos para submissão (português, inglês, espanhol e francês) agregando-lhe conteúdo nacional e internacional. O periódico P2, embora com publicações de fluxo contínuo a partir de 2017, não disponibilizou as edições de 2016 a 2018 online, constatando apenas $28(5,09 \%)$ publicações associadas as TIC. Dessa forma, o P2 foi o periódico com menor quantia de artigos avaliados. Já em P3, apresentou 77 pesquisas pautadas em TIC, abordagens CTS (Ciência, Tecnologia e Sociedade) e CTSA (Ciência, Tecnologia, Sociedade e Ambiente) e Ensino de Ciências em periodicidade semestral em inglês e espanhol.

Tabela 1: Número de publicações anuais por periódico entre os anos 2007 e 2019, bem como o número de artigos por ano pesquisado

\begin{tabular}{c|ccccccc|c}
\hline ANOS & P1 & P2 & P3 & P4 & P5 & P6 & P7 & TOTAL \\
\hline $\mathbf{2 0 0 7}$ & - & 3 & - & 2 & 1 & 0 & - & 6 \\
$\mathbf{2 0 0 8}$ & 7 & 0 & 6 & 2 & 0 & 1 & - & 16 \\
$\mathbf{2 0 0 9}$ & 5 & 1 & 3 & 4 & 2 & 3 & - & 18 \\
$\mathbf{2 0 1 0}$ & 9 & 1 & 2 & 3 & 4 & 2 & 0 & 21 \\
$\mathbf{2 0 1 1}$ & 7 & 2 & 6 & 2 & 6 & 0 & 2 & 25 \\
$\mathbf{2 0 1 2}$ & 5 & 5 & 2 & 4 & 2 & 3 & 15 & 36 \\
$\mathbf{2 0 1 3}$ & 10 & 2 & 2 & 6 & 4 & 1 & 3 & 28 \\
$\mathbf{2 0 1 4}$ & 12 & 6 & 10 & 2 & 4 & 3 & 2 & 39 \\
$\mathbf{2 0 1 5}$ & 17 & - & 7 & 5 & 6 & 2 & 4 & 41 \\
$\mathbf{2 0 1 6}$ & 14 & 0 & 6 & 6 & 4 & 9 & 1 & 40 \\
$\mathbf{2 0 1 7}$ & 27 & 0 & 15 & 16 & 10 & 14 & 6 & 88 \\
$\mathbf{2 0 1 8}$ & 37 & 0 & 12 & 16 & 15 & 25 & 6 & 111 \\
$\mathbf{2 0 1 9}$ & 31 & 8 & 6 & - & 4 & 24 & 8 & 81 \\
\hline TOTAL & 181 & 28 & 77 & 68 & 62 & 87 & 47 & 550 \\
\hline
\end{tabular}

Fonte: Elaborado pelas autoras (2020) 
Quanto ao Periódico P4, constatamos 68 publicações, periodicidade trimestral e nos idiomas inglês, português e espanhol. Seus objetos de pesquisa, além de ciências, biologia, física e química, envolveram muitos estudos na área de geociências e matemática. $\mathrm{O}$ periódico P5, com 62 artigos, possui foco na área de educação em ciências, ética e eficiência, não necessariamente em recursos tecnológicos em sala de aula, embora suas pesquisas abordam metodologias que envolvem tais ferramentas.

O periódico P6, publicado apenas em português e quadrimestral, compreendeu 87 pesquisas com escopo no ensino de ciências; enquanto a revista $\mathrm{P} 7$, de periodicidade quadrimestral nos idiomas português, inglês e espanhol, obteve 47 artigos, com pesquisas voltadas para o ensino de ciências e matemática. Ambas apresentaram diversos estudos com metodologias cientificas voltadas para as ciências exatas em detrimento das ciências naturais.

Tendo em vista os dados apresentados na tabela 1, observamos um crescente impacto evidenciado no aumento de número de pesquisas didático-tecnológica nas ciências naturais entre 2007 e 2019. Essa perspectiva coaduna com Junior et al. (2017, p. 56), ao afirmarem que o avanço das TICs constituíra aplicações amplas em diversas áreas, destacando-se na educação, com interação entre professor e aluno de forma rápida e dinâmica.

Atualmente, a aquisição de informações é efetivada, de modo considerável, pelos smartphones e internet. O percentual de indivíduos que utilizam a Internet cresceu de $40 \%$ para 57,6\% entre 2012 e 2016, no Brasil, segundo uma pesquisa da Anatel (2018, p. 12), embora ainda em patamar inferior aos blocos de países europeus desenvolvidos e em desenvolvimento. Tal perspectiva tem constituído uma realidade gradativamente comum na sociedade brasileira, culminando em alterações políticas, industriais, econômicas, e também em sala de aula que, por conseguinte, influência na pesquisa e extensão na área em prol de seu respectivo crescimento profissional e comunitário. Esta concepção é evidenciada na tabela 1, onde observamos que a demanda por pesquisas em TIC incide na educação progressivamente a partir de 2007, e dobrando o número de pesquisas nesta área a partir de 2016, também estimulada pelo ProInfo.

Vale salientar que a queda na quantidade de publicações em 2019 não diz respeito à redução no número de publicações sobre TIC nas Ciências Naturais, mas devido á indisponibilidade das últimas edições do ano por algumas revistas até o momento analisado. É notório que o periódico P4 não publicou edições em 2019 até o mês de dezembro, onde 
ocorreu a coleta de dados; a revista P5 publicou apenas uma das três edições (periodicidade quadrimestral) por ano, e P3 somente uma de duas edições previstas (periodicidade semestral).

Referente aos níveis escolares constatados nos estudos publicados nos artigos, evidenciamos a disparidade entre a pré-escola e pós-graduação se comparados a graduação e às demais etapas do ensino básico (figura 1). Neste tocante, os dados observados quanto a pré-escola revelam preocupantes implicações neste nível escolar, visto que, a postura de curiosidade para com o mundo natural apresentada na infância remete um possível potencial para a prática inter e transdisciplinar com TIC, seja na elaboração de hipóteses, leitura, observação, registro, discussão e argumentação, ou utilizando-se de atividades lúdicas.

O ensino de ciências compreende um amplo campo de conhecimento, bem estabelecido na educação, embora ainda incipiente na educação infantil. Através da abordagem interdisciplinar no ensino, a criança torna-se sujeito dos produtos culturais humanos e, por conseguinte, protagonistas no desenvolvimento pessoal e coletivo como produtores de cultura sob uma perspectiva crítica. Deste modo, Maline et al., (2018, p. 998) mencionam:

[...] Elas possuem uma capacidade de construir de forma sistematizada, modos de significação do mundo. Acreditamos que a abordagem de ensino por investigação com as crianças pequenas potencializa esse protagonismo ampliando as capacidades das crianças de observar, generalizar, manipular, classificar, indagar, comunicar. Enfim, tal abordagem pode expandir suas possibilidades de exploração do mundo natural, de modo cada vez mais sofisticado e próprio.

Figura 1: Número de artigos averiguados por nível de ensino (2007-2019)

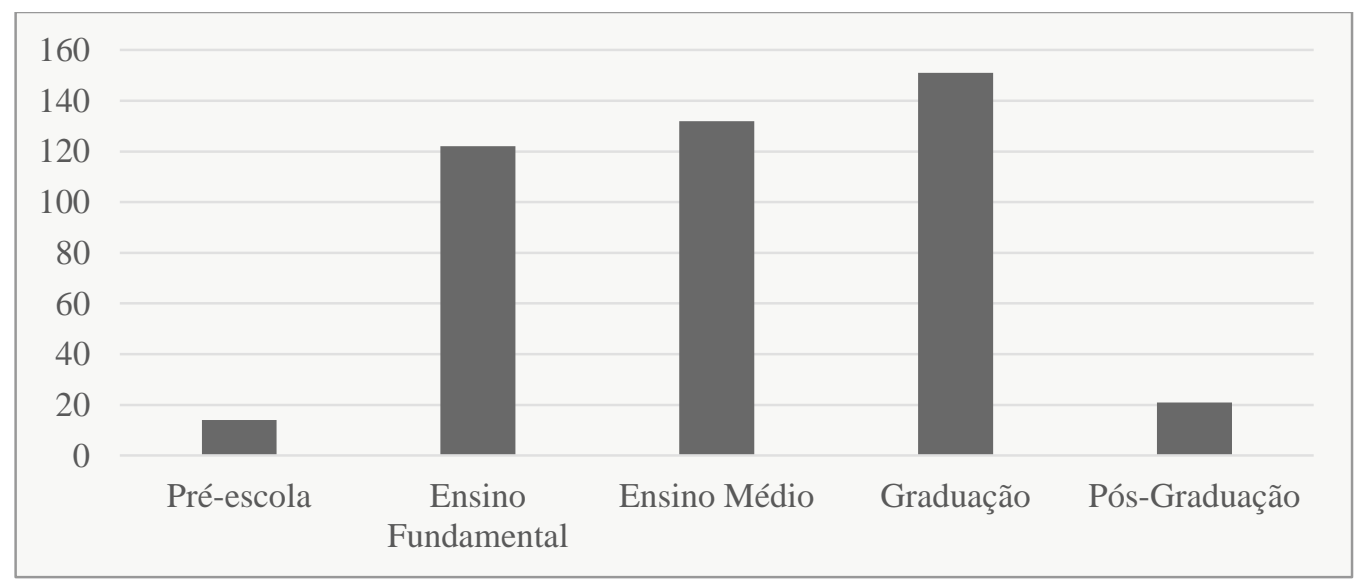

Fonte: Elaborado pelas autoras (2020)

Em "Ensino Fundamental” (figura 1), por sua vez, destacamos 122 artigos, em que a disciplina de ciências se fundamenta em didáticas pautadas no uso de simuladores e jogos 
virtuais, além de práticas pedagógicas voltadas para educação não formal que promovem autodesenvolvimento e o questionamento, tornando o aluno capaz de comandar as atividades com soberania. Assegura-se, portanto, tal concepção no Art. 32, inciso II da LDB nº 9.394, mediante "a compreensão do ambiente natural e social, do sistema político, da tecnologia, das artes e dos valores em que se fundamenta a sociedade" (Lei 9.394, 1996).

Partindo dessa premissa, acreditamos que o número significativo de pesquisas do ensino de ciências com recursos didáticos seja resultado dos avanços tecnológicos no ensino, bem como o uso de metodologias que exploram a práxis destes recursos e, por sua vez, despertam a curiosidade dos alunos.

Em "Ensino Médio", o segundo nível escolar com maior quantidade de publicações (134 artigos) possui uma de suas finalidades, conforme o inciso IV do Art. 35 da LDB- $\mathrm{n}^{\mathrm{o}}$ 9.394, “a compreensão dos fundamentos científico-tecnológicos dos processos produtivos, relacionando a teoria com a prática, no ensino de cada disciplina" (Lei 9.394, 1996). Consoante aos dados obtidos, constatamos que o elevado número de publicações encontradas neste nível escolar delimita perspectivas interdisciplinares na educação, pois, ao se inserir recursos didático-tecnológicos nas disciplinas de ciências naturais, viabilizamos a cooperação entre estes saberes e os de informática e ciências exatas, além de reduzir a visão compartimentalizada dos conteúdos voltados estritamente para vestibulares. Ainda segundo a LDB, o ensino médio compreende a etapa final do ensino básico (Art. 35), responsável pela formação da identidade dos alunos e, por conseguinte, a constituição de uma identidade cidadã crítica.

Quanto ao ensino superior, tópico que engloba a graduação e pós-graduação, vale destacar o inciso III do Art. 43 da LDB- $n^{0}$ 9.394, que visa "investigar o trabalho de pesquisa e investigação científica, visando o desenvolvimento da ciência e da tecnologia e da criação e difusão de cultura, e deste modo desenvolver o entendimento do homem e do meio em que vive" (Lei 9.394, 1996).

Em “Graduação”, nível escolar com maior número de publicações levantadas (151) apresenta a universidade como centro de produção de pesquisas e integração tecnológica, fator benéfico a formação acadêmica, embora gere dados preocupantes em detrimento da escassa disseminação deste saber para a sociedade, como a extensão (13 artigos). Em contrapartida, "pós-graduação", com artigos voltados estritamente para o mestrado, 
compreendeu apenas 21 artigos, de enfoque majoritariamente destinado à Educação a Distância (EAD) e que segundo Ferreira e Voelzke (2014, p. 184):

Estas se apresentam como alternativas para um público que, de outra maneira, não teria acesso a esse tipo de formação a partir do sistema tradicional de ensino presencial, seja devido ao distanciamento geográfico das Instituições de Ensino Superior [IES], possibilidade de horários, custos e outros fatores determinantes.

As modalidades de ensino, por sua vez, visam auxiliar a difusão do ensino de forma acessível, como proposto no inciso I do Art. n 206 da Constituição Federal que assevera "igualdade de condições para o acesso e permanência na escola" (Artigo 206, 1988). Deste modo, se assegura a pluralidade da educação, articulando suas atividades com integração da família e comunidade.

Dos 550 artigos avaliados, 441 mencionaram as modalidades de ensino (figura 2), revelando disparidades na concentração de TIC em Ciências naturais. As pesquisas abordam majoritariamente à Educação Formal, correspondendo a 192 artigos, ao passo que Educação Escolar Indígena apresentou apenas 2. Tal polaridade expressa que há resquícios de uma visão conservadora e restrita à sala de aula como meio fornecedor do saber, além de lacunas na educação tecnológica acessível aos povos indígenas.

Figura 2: Número de artigos apurados por modalidades de ensino encontrados (2007-2019)

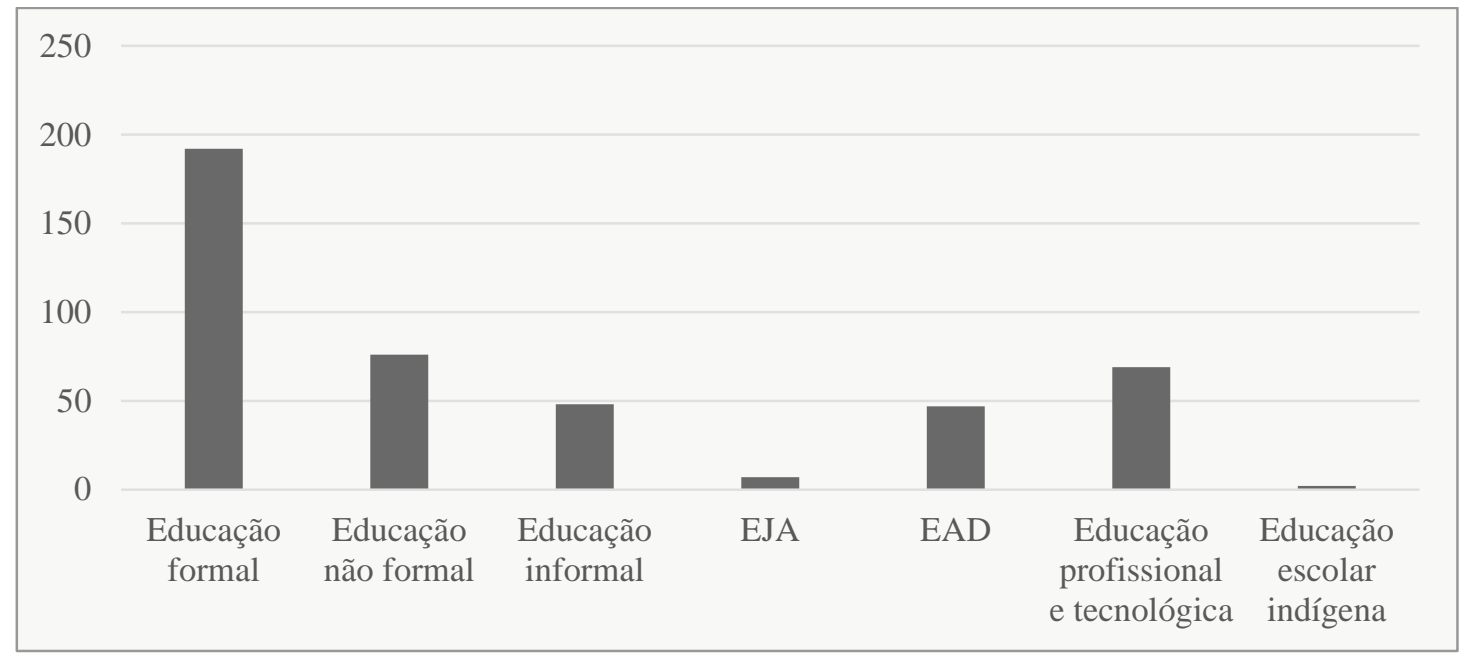

Fonte: Elaborado pelas autoras (2020)

A educação não formal, por sua vez, consiste em metodologias de ensino moldadas externamente ao meio escolar, abrindo novas possibilidades de conhecimento social e investigativo através de museus, planetários, zoológicos, jardins botânicos e bibliotecas. Para Gohn (2010, p. 19), "sua finalidade é abrir janelas de conhecimentos sobre o mundo que circunda os indivíduos e suas relações sociais. Seus objetivos não são dados a priori, eles se constroem no processo interativo, gerando um processo educativo". 
Foram abordadas 76 publicações nesta modalidade, a segunda mais trabalhada, utilizando-se de simulações, fotografia, recursos audiovisuais, GPS, aplicativos para smartphones, e e-books. Nesse compasso, "há que reconhecer as potencialidades de espaços não-escolares na promoção da alfabetização científica da população, considerando as especificidades da ação educativa quando desenvolvida nesses contextos (público, discurso expositivo, objetos, etc.” (Marques \& Marandino, 2019, p. 4).

As 48 publicações voltadas para a educação informal, por sua vez, expressam um quadro preocupante quanto o ensino de TIC em ciências naturais. Na educação informal, segundo Gohn (2010, p.18) “o aprendizado acontece de forma espontânea, não sistematizada e não organizada e os saberes adquiridos são absorvidos no processo de vivência e socialização, pelos laços culturais e de origem dos indivíduos".

Na EJA, o segundo com menor número de artigos encontrados (7), sugerem a ínfima quantidade de artigos de pesquisas nesta modalidade, "consoante a redução de matrículas no Programa entre os anos de 2014 a 2018, com 2,9\%, principalmente no ensino fundamental, com queda de 10,1\%" (Inep, 2018, p. 28). Analogamente, analisando periódicos nacionais para identificar as principais tendências contemporâneas das pesquisas em Educação Ambiental, Bornia e Royer (2020), averiguaram que apenas 3,5\% das pesquisas foram realizadas na modalidade EJA. Portanto, observa-se então uma lacuna nas pesquisas científicas nesta modalidade de ensino.

A EAD, com 47 artigos, expõe a crescente busca por esta modalidade de ensino mediante sua acessibilidade, principalmente quando associada à adequação da carga horaria cotidiana dos estudantes quanto á comunidades que possuem dificuldades para se locomover ao meio escolar. Segundo o Censo Educacional de Ensino Superior de 2018 (Inep, 2019), pela primeira vez no Brasil, os alunos matriculados em cursos de licenciatura à distância $(50,2 \%)$ superaram os presenciais $(49,8 \%)$, fato que corrobora com a importância da tecnologia no ensino acessível do país.

Educação Profissional e Tecnológica, por sua vez, com 69 artigos, expressividade associada ao reconhecimento dentro de um mercado de trabalho e maior preparo para a entrada no ensino superior. Este modelo de educação é parte integrante da Lei no 9.394/96, de diretrizes e bases da educação e é obrigatório nos Estados e municípios.

Em contraste, a Educação escolar indígena apresentou apenas 2 artigos, situação preocupante diante da integração entre cultura e educação com os povos indígenas 
brasileiros. Neste enfoque, Valadares e Pernambuco (2018, p. 820) frisam que "os cursos voltados para as comunidades indígenas representam um desafio e uma oportunidade de pesquisa, principalmente as licenciaturas para ensino de ciências naturais, que buscam preservar as culturas indígenas".

Destarte, ações de integração e formação continuada de professores em prol de constituir um elo entre a disseminação da alfabetização científica através de TIC e a preservação da cultura indígena manifestam-se como os desafios para o progresso desta modalidade de ensino no Brasil. Ademais, a estruturação curricular e metodológica na cultura indígena pode ser facilitada a partir da proximidade destes povos com o meio natural, onde conteúdos que permeiam as ciências se fazem presentes em seu cotidiano. Um exemplo desta prática se encontra no estudo articulado por Araújo et al. (2017) ao abordar astronomia à três povos indígenas brasileiros (Guarani, Tukano \& Tembé-Tenetehara), os quais, segundo os autores, demonstraram grande interesse mediante suas crenças religiosas, além da abordagem de extensão universitária possibilitar o compartilhamento de conhecimentos entre o meio acadêmico e cultural destas comunidades.

Os dados levantados relativos as disciplinas que utilizaram as TIC como recursos didático-pedagógicos entre 2007 e 2019 estão ilustrados na figura 3. Em alusão a estes, se observa com maior expressividade na disciplina de Ciências (141 artigos), seguido de Biologia (119), Física (86) e Química (85).

Figura 3: Número de artigos por disciplinas em que as TIC foram aplicadas (2007-2019)

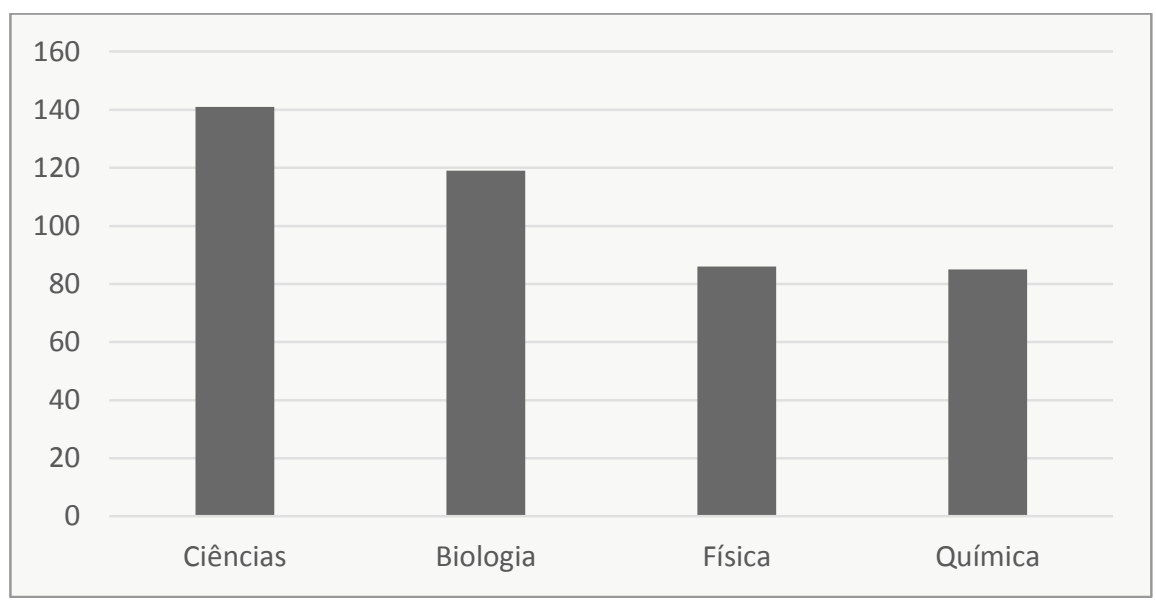

Fonte: Elaborado pelas autoras (2020)

Provavelmente a maior ênfase em Ciências se deve ao fato de os periódicos estipularem prioridade nesta disciplina. Além da reformulação da alfabetização científica, evidenciamos que o locus de ensino não se restringe apenas a sala de aula, mas expande-se à diversas instituições externas a fim de compactuar com o ensino experimental (como elo 
entre teoria e prática) e formação continuada de professores ao estimular a atualização de progressos científicos.

Os dados dos Parâmetros Curriculares Nacionais (Ministério da educação, 2006) demonstram oposição à metodologia conservadora de ensino, onde a Física pauta-se na resolução de problemas utilizando-se uma fórmula específica, fato que leva, na maioria dos casos, a memorização do conteúdo, e não necessariamente o desenvolvimento das competências exigidas. A aplicação das TIC como instrumentos interdisciplinares no ensino de Física compreendeu 86 pesquisas, cujos principais conteúdos trabalhados foram astronomia (38 artigos) e mecânica (24).

A astronomia compreende uma ciência antiga que marcou diversos debates científicos, possibilitando alternativas metodológicas de ensino como o manejo de telescópios e lunetas, visitas a planetários e uso de softwares como Stellarium, um aplicativo para smartphones presentes em 13 artigos, e Celestia, um software 3D mencionado em 8 pesquisas.

Para Frederico e Gianotto (2013, p. 73), ao fornecer as instruções das tecnologias utilizadas, os alunos desenvolvem gradualmente certa autonomia, responsável por induzir confiança para realizar outras simulações de forma independente, além de compartilhar experiências. Outra vantagem, abordada por Mendes, Rehfeldt e Neide (2017, p. 25) corresponde à praticidade e rapidez de laboratórios virtuais, uma vez que as dificuldades comumente encontradas no ensino presencial correspondem a um limitado período de tempo (uma ou duas aulas) para realizar a locomoção dos estudantes ao laboratório, organização de materiais, coleta de dados e discussão dos resultados. No entanto, a implantação de tecnologias na instituição escolar exige infraestrutura, recursos financeiros e preparo docente, fatores tidos como grandes desafios para muitas comunidades carentes no Brasil.

Outrossim, vale salientar a polarização na distribuição dos conteúdos de física, predominando astronomia e mecânica em detrimento, por exemplo, de eletromagnetismo (9), ondas (8) e termodinâmica (2).

De acordo com Paulleti e Catelli (2018, p. 251), diversos pesquisadores têm empregado recursos tecnológicos em prol de superar dificuldades na representação de conceitos da disciplina de química, sobretudo em níveis microscópicos. Não obstante, três professores entrevistados em seu estudo relataram ter acesso ao laboratório de informática 
da instituição, embora sua utilização não se apresentasse viável nem compatível com a carga horária reduzida.

Contudo, a experimentação torna-se essencial ao aprendizado de química, visto que, como ciência natural, relaciona-se com o meio externo, cuja transmissão teórica reduz a probabilidade de aquisição efetiva do conteúdo pelo aluno, como ao trabalhar isomeria química utilizando modelagem computacional (Paulleti \& Catelli, 2018).

Referente à disciplina de Biologia, embora expondo a quantia expressiva de 119 artigos, testemunhou dificuldades de cunho docente quanto á formação continuada (Reis et al., 2016), memorização de informações e restrição didática no espaço de ensino formal (Andrade \& Abílio, 2018), ausência de interdisciplinaridade (Monteiro, Lopes \& Leão, 2019) e formação inicial em Ciências Biológicas descontextualizada (Duré \& Abílio, 2019).

O fomento do saber biológico pauta-se na compreensão dos fenômenos naturais intrínsecos à conhecimentos químicos e físicos, disciplinas ensinadas de modo segmentado e sob perspectivas facilitadoras de ensino, tangentes a memorização e de encontro a sua compreensão integral. Deste modo, a inserção de TIC propõe alternativas facilitadoras desta integração, como a utilização de simuladores, Microscópios, softwares, AVA e laboratórios virtuais.

Contudo, o diálogo entre as disciplinas não deve se restringir ao ensino superior, visto que a experimentação através de recursos tecnológicos no ensino básico atua como via integradora e essencial no desenvolvimento cognitivo e cultural dos estudantes. A formação inicial e continuada, portanto, possuem o papel essencial de viabilizar o ensino de ciências naturais através de constantes atualizações em práticas pedagógicas e avanços científicos.

Quanto às subáreas da Biologia que ocorreu as pesquisas dos artigos avaliados (figura 4), a Educação Ambiental se destacou com 20 menções, enquanto Paleontologia e Educação sexual com uma e duas pesquisas, respectivamente. Se observa disparidade entre as áreas da biologia associadas à CTS e lacuna na utilização das TIC nestas subáreas. 
Figura 4: Subáreas da Biologia constatadas nos artigos (2007-2019)

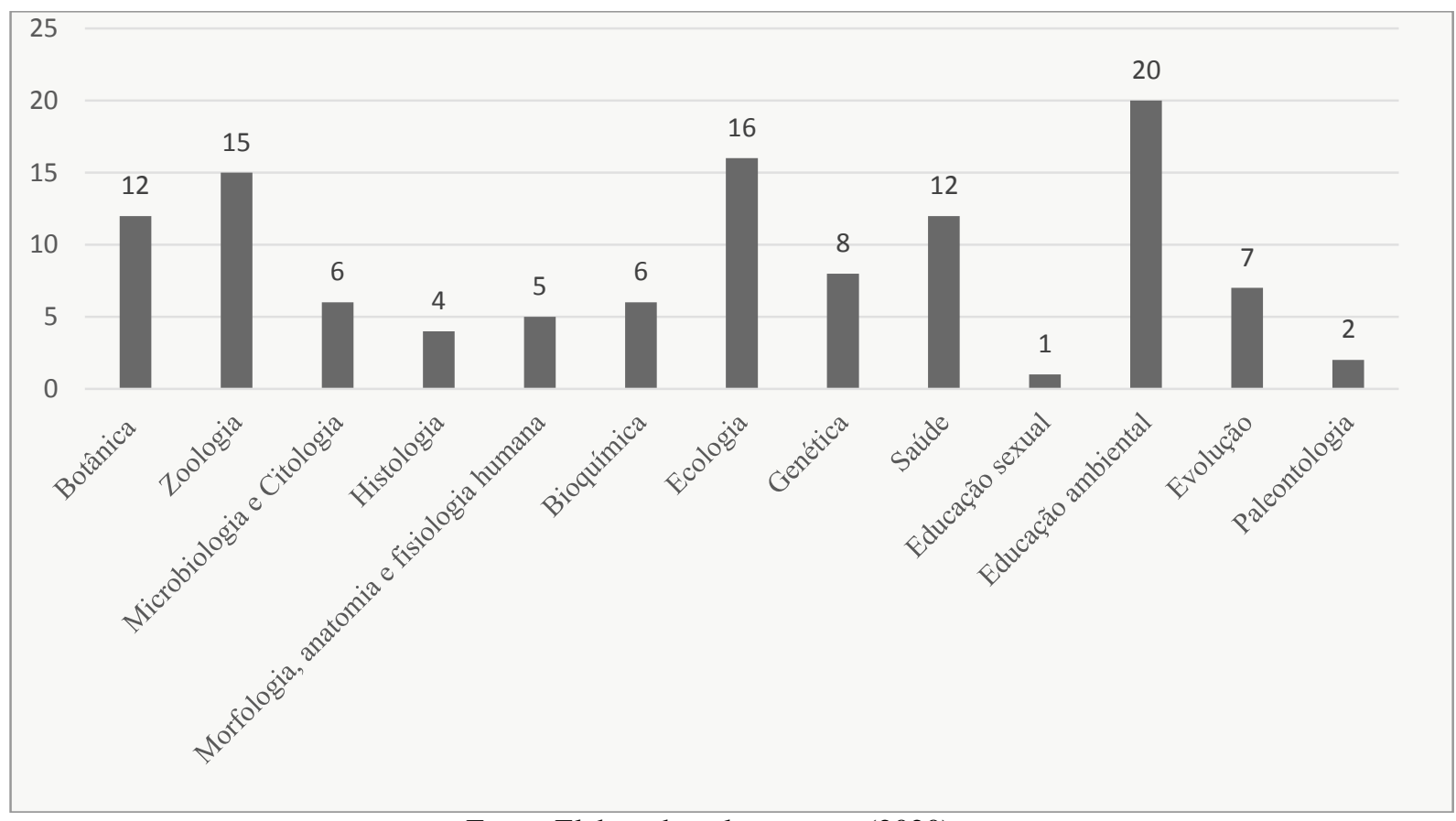

Fonte: Elaborado pelas autoras (2020)

Segundo a Lei $n^{\circ}$ 9.795, que dispõe sobre a Política Nacional de Educação Ambiental (Lei 9.795, 1999), Educação ambiental (EA) fundamenta-se a aquisição de consciência crítica ecológica de cunho coletivo, jurídico, corporativo e didático, visando superar as adversidades ambientais do século XXI. Apesar de concentrar o maior número de publicações quanto às subáreas de biologia, é perceptível a escassez de interdisciplinaridade e restrição à fundamentos ecológicos, trabalhados majoritariamente nas disciplinas de biologia, geografia e datas comemorativas associadas. No entanto, a EA possibilita diversas vias de TIC na biologia, como a fotografia, vídeos e redes sociais.

Quanto à Paleontologia, a problemática quanto aos trabalhos de TIC englobam a limitadas visitas escolares a espaços não formais de ensino, como os museus, mediante o transporte, organização e gasto financeiro, além de terminologias que dificultam a compreensão do estudante, como apontado por Pereira e Valle (2017, p. 843):

[...] os textos podem dificultar o entendimento do público visitante. Uma vez que o público é amplo e heterogêneo, seria necessária uma variedade de textos que contemplasse essa diversidade, tanto em relação à estrutura quanto à linguagem utilizadas, já que se espera que o interlocutor seja considerado na construção.

Por conseguinte, em Educação Sexual, apesar de discutida nos PCN, foi debatida em somente um artigo, fato que "ocorre principalmente devido à crença entre responsáveis pelos estudantes de uma suposta influência dos professores do colégio sobre a sexualidade dos alunos" (Filho \& Sousa, 2017, p. 329). Tais conflitos referentes a inserção da educação 
sexual na escola impossibilitam o docente de aplicar o conteúdo com segurança, restringindo-se a explicações anatômicas e fisiológicas e não necessariamente orientando o aluno a evitar possíveis doenças, impactos sociais e psicológicos relacionados.

Constatamos ainda, em Evolução (7 artigos), adversidades quanto sua inserção perante o tempo escasso disponibilizado, reclamações externas a instituição escolar que convergem com o tema e ausência de materiais, embora as orientações educacionais provenientes dos PCN assegurem a evolução como tema inerente desta disciplina. No Brasil, "estes documentos salientam ainda que a evolução biológica é um dos temas integradores da Biologia e que seu ensino deve permitir que os alunos confrontem distintas explicações sobre a temática” (Reis et al., 2017, p. 51).

De modo geral, as tecnologias utilizadas nas subáreas da biologia que foram evidenciadas nos artigos estudados foram: PhET (8), Scratch (1), NVivo (2), Easy Java simulations (2), Windows Movie Maker (4), fotografia (7), cinema (2), documentários (8), CD’s (3), gravador de áudio (3), Office Power Point (10), GPS (5), Google Earth (2), Khan Academy (2), Moodle (8), Teleduc (2), Blog (12), Redes sociais (9), Portal Universia (2), Email (5), termociclador (3) e Microscópio (6).

Acerca dos enfoques temáticos dispostos nas publicações (figura 5), o tópico Currículo, com 40 publicações, não se resume apenas ao debate de documentos oficiais norteadores de práticas pedagógicas, mas ampliando-se a práticas docentes pautadas em documentos curriculares prévios testados e propostas que visam acompanhar os avanços tecnológicos atuais.

Em Formação de Professores, com 105 pesquisas destacadas, a perspectiva estruturase em torno da formação inicial e continuada de professores a fim de atender a demanda por profissionais competentes aos novos eixos atuais de cunho digital e contextualizado. Um desafio para a integração efetiva das TIC na instituição escolar do século XXI compreende a capacitação de docentes cuja formação acadêmica inicial fundamentou-se em abordagens tradicionais de ensino, culminando em diversas propostas de formação continuada. Contudo, o cenário vigente consiste na extensa permanência destes profissionais em sala de aula para trabalho remunerado, em diversas turmas, escolas e simultâneo desgaste oriundo da locomoção, como ressalta Pugliese $(2017,973)$ :

O trabalho feito de modo individual e basicamente mecânico. Não há tempo disponível para a articulação entre professores, para o trabalho reflexivo ou para a pesquisa e a 
investigação dos problemas cotidianos e da busca por mudanças educacionais ou inovações, nem sequer de implementações de reformas impostas por forças externas.

Figura 5: Enfoques temáticos apresentados nos artigos estudados (2007-2019)

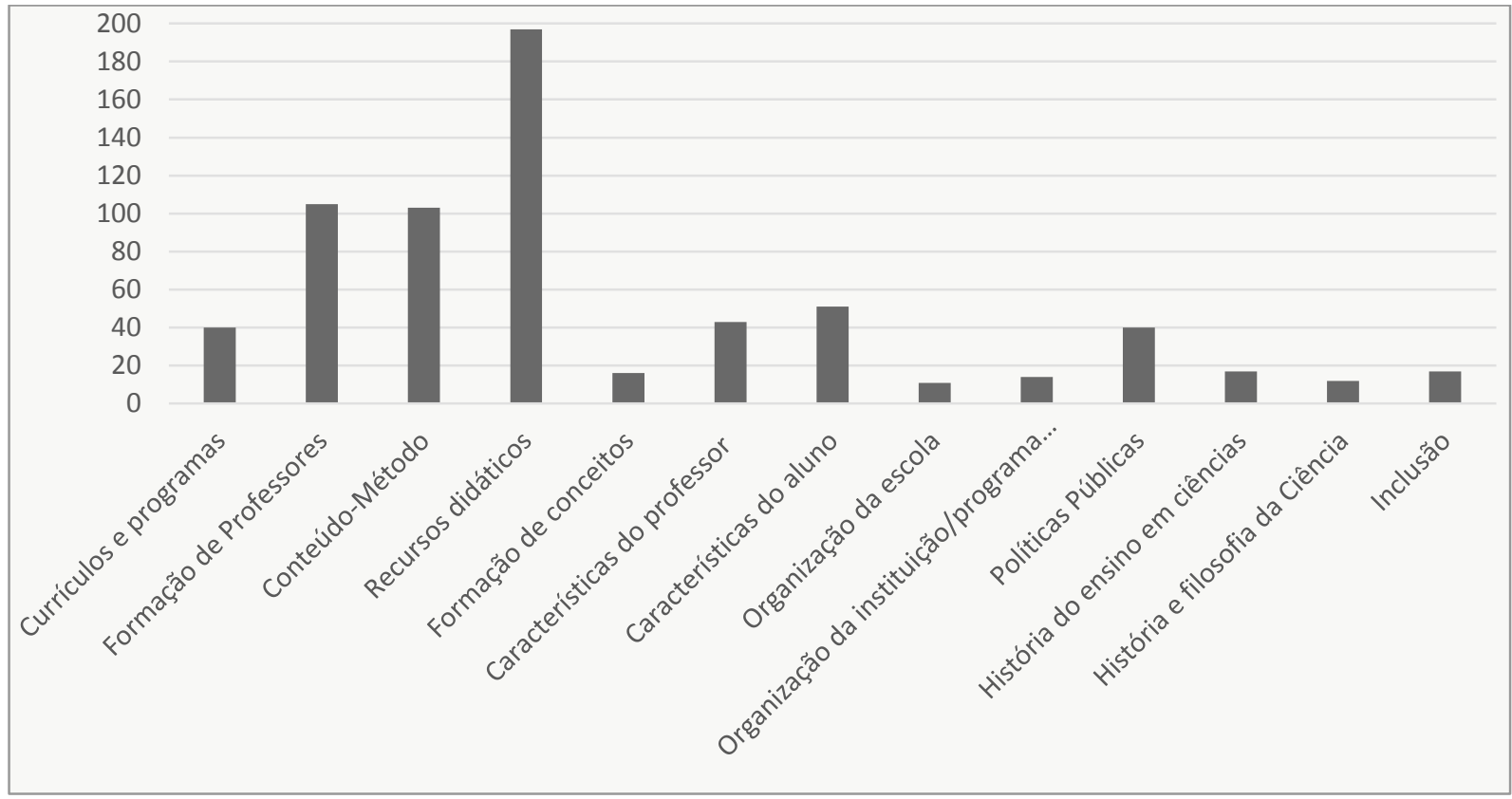

Fonte: Elaborado pelas autoras (2020)

Deste modo, as implicações relacionadas a inflexibilidade docente de conciliar o trabalho com a educação continuada e atualizações no meio científico delimitam desafios a serem superados na Educação brasileira.

Em Conteúdo-método, notamos resultados positivos quanto á integração de metodologias inovadoras e interdisciplinares mencionadas em 103 publicações, valor relacionado a necessidade de aplicar o conhecimento de maneira interdisciplinar, além de "integrar o uso das tecnologias como ferramenta auxiliar no desenvolvimento desse conteúdo na aprendizagem dos alunos" (Freitas \& Chassot, 2017, p. 198).

O tópico com maior quantidade de publicações foi Recursos didáticos com 197 publicações, destacando os recursos TIC trabalhados ou propostos em pesquisas educacionais. Estes são especificados e quantificados, conforme visualizamos na figura 6. 
Figura 6: Recursos didático-tecnológicos utilizados nos artigos estudados (2007-2019)

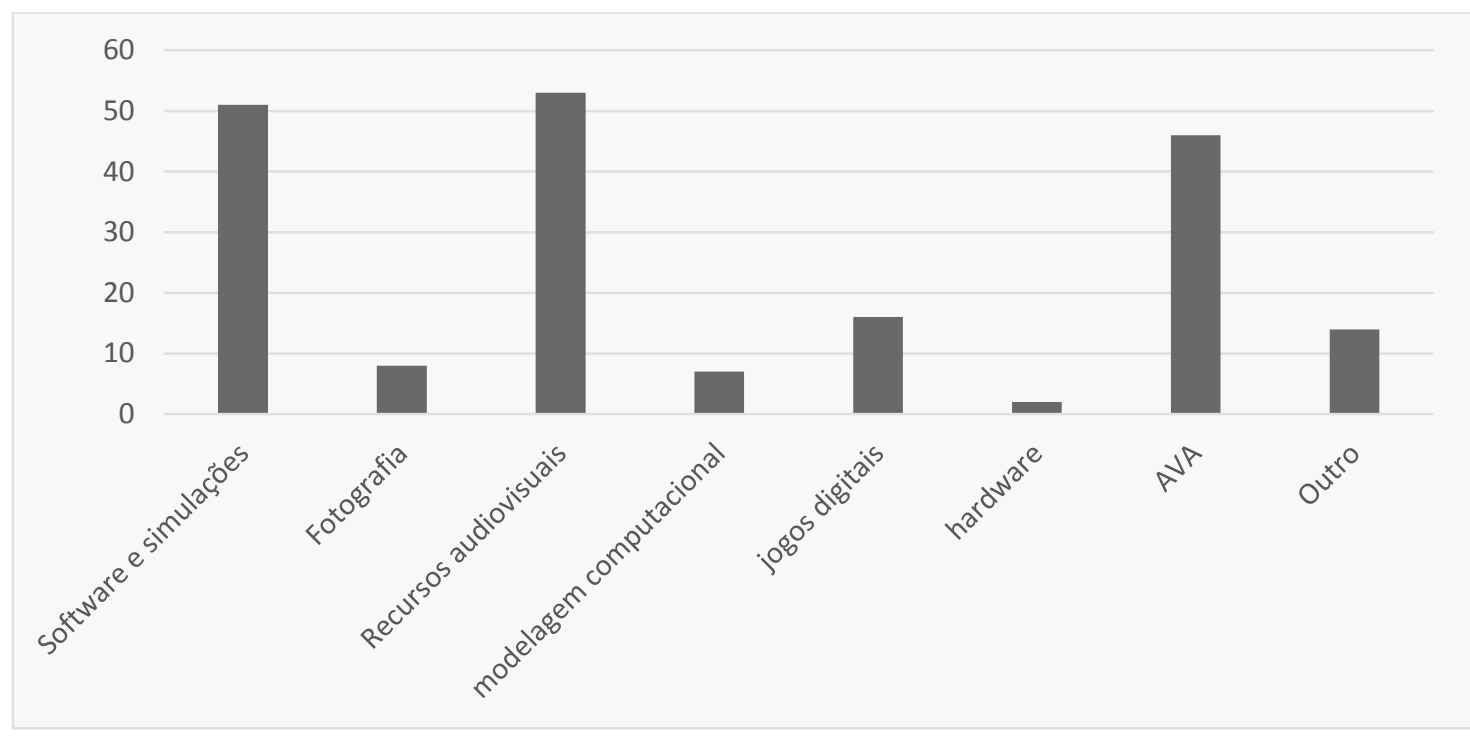

Fonte: Elaborado pelas autoras (2020)

Os recursos didático-tecnológicos trabalhados nas disciplinas de ciências, biologia, química e física, descritos quantitativamente na figura 6 , foram classificados de acordo com sua funcionabilidade nos tópicos abaixo.

Os softwares e simulações utilizadas agregam utilidades diversas, tais como praticidade, mobilidade e autonomia. De acordo com Trentin, Silva e Rosa (2018, p. 101):

Por intermédio dos simuladores os estudantes têm a oportunidade de planejar, analisar e executar a estratégia acerca da animação que busca desenvolver e depois visualizá-los e refletirem. Outra contribuição que os simuladores virtuais agregam é a interação entre componentes de um grupo, quando a atividade requer tomada de decisões.

Tal funcionabilidade compreendeu 51 publicações que usufruíram destes recursos para o ensino de ciências naturais, os quais compreendem: PhET (10 menções), Scratch (3), Sobek (1), Nvivo (2), Atlas_ti (1), Edmodo (3), Prezi (1), Inventor (2), Easy Java Simulations (2), Stellarium (13), Cellestia (8), DataOne (1), Google Earth (2) e Tracker (2). Destes PhET, Easy Java Simulations, Tracker, Stellarium e Cellestia compreendem programas de simulação; Inventor e Scratch são softwares de programação computacional; Nvivo, DataOne e Atlas_ti são utilizados para a análise qualitativa de dados; Edmodo, Prezi e Sobek atuam na computação e armazenamento de dados em nuvem e; Sobek como ferramenta na mineração de dados.

Na categoria Fotografia, encontramos oito artigos mencionando o uso de câmeras digitais na atividade de campo, propiciando engajamento com a educação ambiental e registro de atividades não-formais mediante uma ferramenta tecnológica. Somado a isso, 
Recursos audiovisuais, com 53 pesquisas, empregaram as TIC de forma majoritariamente lúdica, através de documentários (8), cinema (10), filmadora (9), gravação de áudio (8), CD’s (3). Incluímos nesta classificação os softwares Microsoft office Power Point (12), Educaplay (2), Screencast O'Mastic (1) e Windows Movie Maker (5) devido a sua finalidade também audiovisual.

Os recursos de Modelagem computacional não foram utilizados com expressividade nas publicações, mencionados em apenas sete artigos, cujos programas utilizados foram o Moodelus (5) e Diagrama AVM (2). Os jogos digitais, por sua vez, foram trabalhados em 16 artigos, correspondentes a apenas 2 tópicos: Khan Academy (10) e os demais (6) desenvolvidos pelos próprios autores dos artigos. Em Hardware, encontramos apenas o Arduíno, em dois artigos.

Os Ambientes Virtuais de Aprendizagem (AVA) apresentaram maior expressividade ao destacarem-se em 46 pesquisas, visto que disponibilizam uma interface dinâmica, prática, além de serem pontos cruciais na inclusão de alunos deficientes. As plataformas de AVA utilizadas nos estudos bibliográficos para tais fins compreendem: Moodle (8), ProInfo (2), Teleduc (2), Blogs e Fóruns online (13), E-mail (5), Redes Sociais (14) e Portal Universia (2).

$\mathrm{Na}$ categoria "Outro", com 14 artigos totais, encontramos termociclador (3), microscópio (6), Telescópio (1), GPS (3), Multímero (1).

No entanto, segundo Estevão e Passos (2015, p. 210).

[...] apesar de estados e municípios estarem constitucionalmente obrigados a aplicar recursos na educação básica, não significa que contemplem, nas ações de manutenção e desenvolvimento do ensino (MDE), tecnologias de informação e de comunicação. Esta é uma escolha e, por conseguinte, depende da discricionaridade do gestor ou de um mecanismo indutor que potencialize os ganhos e minimize os custos. A ausência deste e, principalmente, a ampliação dos custos sem qualquer garantia de ganhos, atua desfavoravelmente na assunção das atribuições pactuadas quando da adesão ao ProInfo.

Embora a abordagem de práticas inovadoras de ensino em Ciências Naturais, o investimento necessário para sua implantação não atua exatamente de acordo com o ProInfo, visto que diversos estados e municípios não contemplam dos recursos necessários para ampliar esta metodologia de ensino.

Em alusão aos enfoques temáticos observados na pesquisa (figura 5) destacamos a presença da temática Formação de Conceitos, que por sua vez, entende-se não somente conceitos elaborados pela comunidade científica, mas concepções empregadas “em uma rede 
complexa de relações com outros conceitos e o uso deliberado dos mesmos" (Costa; Echeverría \& Ribeiro, 2017, p. 807). Por conseguinte, o reflexo da formação de uma consciência crítica pautada em TIC pelos estudantes brasileiros posiciona-se em um cenário preocupante, onde apenas 16 pesquisas, dentro do recorte de pesquisa avaliada, debateram a respeito de suas implicações em ciências naturais.

Nos tópicos Características do Professor e Características do aluno referente a figura 5, respectivamente com 43 e 51 publicações, destacam o reconhecimento da contextualização histórica destes indivíduos em meio escolar, visto que muitos professores são imigrantes digital, o os alunos, nativos digitais.

Outrossim, Organização da escola, organização da instituição/programa não escolar, história do ensino em ciências e história e filosofia da ciência, respectivamente com 11, 14, 17 e 12 pesquisas pontuadas, delimitam a escassez de pesquisas voltadas à conciliação de meios formais e não formais de ensino, além da ínfima integração das ciências humanas que vão de encontro à política estipulada pela CTS, onde:

[...] as instituições educativas, como centro de formação cidadã, devem ter a preocupação de possibilitar oportunidades para que o indivíduo, ali presente, desenvolva as capacidades de atuar ativamente na sociedade. Esta atuação se refere à maneira como ele se posiciona frente aos desafios e como elabora soluções para as questões-problemas do meio em que vive (Scheid, 2018, p. 444).

Os levantamentos de Políticas públicas correspondendo a 40 publicações, destacaram-se o ENEM (11 publicações), PCN (9), DCN (8) e BNCC (8). Neste tocante, os documentos oficiais brasileiros expõem a necessidade de implementação das TIC, visando a formação de alunos competentes quanto á habilidades socioculturais e contextualizadas no ensino básico e superior.

Outro tópico preocupante encontra-se em Inclusão, com apenas 17 artigos, embora a Lei de Diretrizes e Bases da Educação Nacional n ${ }^{0}$ 9.394/96, artigo 58 reforce a educação inclusiva no Brasil e: "Entende-se por educação especial [...] a modalidade de educação escolar oferecida preferencialmente na rede regular de ensino, para educandos com deficiência, transtornos globais do desenvolvimento e altas habilidades ou superdotação" (Lei 9.394, 1996).

De modo complementar, adversidades encontradas neste tópico abrangem a formação precária quanto ao conhecimento sobre deficiências, formas de trabalho que possibilitem a integração do aluno, carência de programas de formação continuada que 
contemplem o trabalho com estes estudantes e as limitadas deficiências abordadas nas pesquisas, a qual evidenciamos somente surdez (9 publicações), deficiência visual (7) e disfemia (1), não constatando-se, por exemplo, TDAH, dislexia, autismo, asperger, dentre outras.

Por fim, quanto as implementações das TIC na inclusão, de acordo com o estudo de Gonçalves, Andrade e Szmoski (2019, p. 607), o uso da plataforma Moodle como recursos audiovisuais de ensino na complementação do ensino da disciplina de libras para acadêmicos ouvintes contribui positivamente na comunicação, socialização e desempenho dos estudantes ao utilizarem desta tecnologia. No entanto, o ensino de química encontra-se debilitado tratando-se de adequações aos deficientes visuais, em especial tratando-se de conceitos abstratos, moleculares e espaciais, pois "o deficiente visual necessita de ferramentas que minimizem a barreira do acesso à informação e assim, os auxilie a construir uma aprendizagem significativa" (Paulo, Borges \& Delou, 2018, p. 2).

\section{Considerações Finais}

Face aos avanços tecnológicos presenciados no século XXI, seu impacto inerente na instituição escolar culmina em elaborações de estratégias didáticas e estruturais que acompanhem tais mudanças. Diante da aquisição de smartphones, acesso à internet e softwares de funcionabilidade ampla e dinâmica, o professor assume o papel de mediador da aprendizagem dos alunos, dissolvendo perspectivas arcaicas de compartimentalização de ensino e implantando a interdisciplinaridade. No entanto, a capacitação deste profissional no contexto atual do Brasil remonta a necessidade emergente da formação continuada para professores cuja formação acadêmica não contemplou as TIC e estratégias de inclusão no ensino.

Para a inserção das TIC na educação, faz-se essencial uma adequada infraestrutura, recursos financeiros e formação docente. Em um país em desenvolvimento, no entanto, muitas comunidades carentes encontram-se desprovidas de tais fatores, contexto responsável por grandes desafios a serem enfrentados na educação de nosso país.

Os níveis de ensino trabalhados nas pesquisas demonstraram nítida polarização, visto que as publicações priorizaram o ensino fundamental, médio e graduação, em detrimento da pré-escola e pós-graduação. 
Outrossim, as modalidades de ensino expressaram preocupações socioculturais ao empregarem de forma ínfima os recursos tecnológicos na educação escolar indígena, devido ao receio dos docentes em implicações negativas do ensino de ciências nas vertentes religiosas dessas comunidades. EJA também foi pouco trabalhada devido a impossibilidade de contextualização do ensino perante a carga horária imposta aos professores. Em contraste, a educação formal permanece como prioridade nos estudos levantados, embora tenhamos manifestado crescentes enfoques na educação não formal, tido como integrador na atualização de docentes e alunos as descobertas científicas, desenvolvimento sociocultural, associação de conceitos cotidianos e exercício da práxis pedagógica. Vale destacar a gradual procura pela modalidade EAD de ensino, especialmente nos cursos de licenciatura.

Dentre áreas mais pesquisadas na Biologia, a Educação ambiental revelou dados positivos quanto à interação com outras disciplinas, como geografia, geologia, química e física, ao passo que o elevado número de estudos deste âmbito talvez sejam provenientes do significativo aumento dos debates ambientais presenciados atualmente, seja em conferências e elaboração de documentos como a agenda 2030, como no impacto cotidiano de desastres ambientais e alterações climáticas cada vez mais expostas na mídia e presenciadas no cotidiano dos estudantes.

Podemos destacar como aspecto positivo o considerável fomento de pesquisas com enfoque no uso de TIC no ensino de Ciências e Biologia de 2007 a 2019, constatando o esforço contínuo dos docentes em meio às adversidades apresentadas em prol de um ensino acessível e de qualidade no Brasil.

\section{Referências}

Anatel (2018). Relatório Anual 2018 - Agência Nacional de Telcomunicações. Anatel Agência Nacional de telecomunicações. https://sei.anatel.gov.br/sei/modulos/pesquisa/md_pesq_documento_consulta_externa.p hp?eEPwqk1skrd8hSlk5Z3rN4EVg9uLJqrLYJw_9INcO5qCMSr1EMcIpgzizi6JB11Zf IGUkLQFuv-nQ2rlXU4epBnwl_RtrJMm4TFmg79Z9fViw1qMyG2njP4-8SlBgOO.

Andrade, M. J., \& Abílio, F. J. (2018). Alfabetização científica no ensino de biologia: Uma leitura fenomenológica de concepções docentes. Revista Brasileira de Pesquisa em $\begin{array}{lllll}\text { Educação } \quad \text { Ciencias, } & \text { 18(2), } & \text { 429-453. }\end{array}$ https://doi.org/10.28976/19842686rbpec2018182429

Araújo-Costa, D. C., Verdeaux-Silva, M. F. \& Cardoso-Thomazi, W. (2017). Uma proposta para a inclusão de tópicos de astronomia indígena brasileira nas aulas de Física do Ensino Médio. Ciência \& Educação, 23 (4), 1035-1054. https://doi.org/10.1590/1516$\underline{731320170040011}$ 
Bornia, B. G. \& Royer, M. R. (2020). Pesquisas brasileiras em Educação Ambiental que estão em voga atualmente: Uma análise de periódicos nacionais. Research, Society and Development, 9 (4), 1-20. http://dx.doi.org/10.33448/rsd-v9i4.2979

Congresso Nacional do Brasil. (1996, 20 de dezembro). LDB - Lei no 9.394 de 1996. Lei de $\begin{array}{lllll}\text { Diretrizes } & \text { e } & \text { Bases }\end{array}$ http://www.planalto.gov.br/ccivil_03/leis/19394.htm

Congresso Nacional do Brasil. (1999, 27 de abril). Lei no 9.795 de 1999. Política Nacional de Educação Ambiental. http://www.planalto.gov.br/ccivil_03/leis/19795.htm.

Congresso Nacional do Brasil. (2007, 12 de dezembro). Decreto no 6.300 de 2007. Programa Nacional de Tecnologia Educacional http://www.planalto.gov.br/ccivil_03/_Ato2007-2010/2007/Decreto/D6300.htm.

Constituição da República Federativa do Brasil (1988, 5 de outubro). Artigo no 206 de 1988. Brasília. http://www.planalto.gov.br/ccivil_03/constituicao/constituicao.htm.

Costa, L. S., Echeverría, A. R. \& Ribeiro, F. L. (2017). O Processo de tomada de consciência e a formação de conceitos da educação ambiental na formação inicial de professores de ciências/química. Revista Brasileira de Pesquisa em Educação em Ciências, 17(3), 803834. https://doi.org/10.28976/1984-2686rbpec2017173803

Cruz, J. A., Arxer, E. A., Cunha, A. K. \& Bizelli, J. L. (2018). Novas tecnologias, Trabalho e educação: Um debate interdisciplinar. Revista Internacional de Formação de Professores, 3(1), 99-108.

Duré, R. C. \& Abílio, F. J. (2019). A formação inicial na concepção docente: Um estudo fenomenológico com professores de ciências biológicas. Revista Brasileira de Pesquisa em Educação em Ciências, (19), 345-371. https://doi.org/10.28976/19842686rbpec2019u345371.

Estevão, R. B. \& Passos, G. O. (2015). O programa nacional de tecnologia educacional (PROINFO) no contexto da política educacional brasileira. Revista Holos, 31(1), 199210. https://doi.org/10.15628/holos.2015.2645.

Ferreira, O. R. \& Voelzke, M. R. (2014). Educação a distância: A humanização da tecnologia numa perspectiva freireana. Revista de Produção Discente em Educação Matemática, 3(1), 137-149.

Filho, R. S., \& Souza, I. C. (2017). Subjetividade e ensino de ciências: uma discussão sobre sexualidade na escola através do olhar docente. Revista Brasileira de Ensino de Ciência e Tecnologia, 10(3), 321-343. http://dx.doi.org/10.3895/rbect.v10n3.5246.

Frederico, F. T. \& Gianotto, D. E. (2013). Tecnologia e ensino de ciências: possibilidades e desafios. ARETÉ-Revista Amazônica de Ensino de Ciências, 6(11), 65-82.

Freitas, E. B., \& Chassot, A. I. (2017). Obstáculos epistemológicos no uso de TIC no ensino de ciências. ARETÉ-Revista Amazônica de Ensino de Ciências, 10(22), 194-202.

Gohn, M. da G. (2010). Educação não formal e o educador social - atuação no desenvolvimento de projetos sociais. Cortez.

Gonçalves, F. B., Andrade, R. de B. \& Szmoski, R. M. (2019). Utilização da plataforma Moodle para avaliação na disciplina de Libras para ouvintes no ensino superior: um estudo de caso. Revista Brasileira de Ensino de Ciência e Tecnologia, 12(1), 598-611. http://dx.doi.org/10.3895/rbect.v12n1.9702. 
Inep. (2018). Instituto Nacional de Estudos e Pesquisas Educacionais Anísio Teixeira. Censo Escolar 2018.

MEC. http://download.inep.gov.br/educacao_basica/censo_escolar/resumos_tecnicos/resumo _tecnico_censo_educacao_basica_2018.pdf

Inep. (2019). Instituto Nacional De Estudos E Pesquisas Educacionais Anísio Teixeira. Censo da Educação Superior 2018: notas estatísticas. http://download.inep.gov.br/educacao_superior/censo_superior/documentos/2019/apres entacao_censo_superior2018.pdf.

Junior-Szesz, A., Silva-Rutz, S. C., Vaz-Gomes, M. S., \& Bittencourt-Falcão, D. (2017). Acessibilidade em ambiente virtual de Aprendizagem. Revista Brasileira de Ensino de Ciência e Tecnologia, 10(1), 55-64. http://dx.doi.org/10.3895/rbect.v10n1.5692.

Maline, C., de Sá, E. F., Maués, E., \& Souza, A. de C. (2018). Ressignificação do Trabalho Docente ao Ensinar Ciências na Educação Infantil em uma Perspectiva Investigativa. Revista Brasileira de Ensino de Ciência e Tecnologia, 13(3), 993-1024. https://doi.org/10.28976/1984-2686rbpec2018183993.

Marques, A. \& Marandino, M. (2019). Alfabetização científica e criança: análise de potencialidades de uma brinquedoteca. Ensaio-Pesquisa em Educação em Ciências, 21 (1)21, 1-25. https://doi.org/10.1590/1983-21172019210102.

Megid Neto, J. (1998). O ensino de Ciências no Brasil: catálogo analítico de teses e dissertações, 1972-1995. Campinas: UNICAMP/FE/CEDOC.

Mendes, E., Rehfeldt, M., \& Neide, I. (2017). Exploração de simulações como forma de estimular o aprendizado de conceitos da Cinemática Escalar. Revista Brasileira de Ensino de Ciência e Tecnologia, 10(2), 1-29. http://dx.doi.org/10.3895/rbect.v10n2.2694.

Ministério da Educação, Secretaria de Educação Média e Tecnológica. (2006). Parâmetros curriculares nacionais: Ciências Naturais. Brasília: MEC/SEF http://portal.mec.gov.br/seb/arquivos/pdf/livro04.pdf.

Monteiro-Andrade, A. S. F., Lopes-Brayner, F. M., \& Leão, A. M. (2019). Mobilizando os saberes docentes: Rumo à compreensão dos processos biológicos em uma perspectiva sistêmico-complexa. Revista Ensaio em Pesquisa em Ação em Ciências, (21), 1-22. https://doi.org/10.1590/1983-21172019210101.

Moreira, M. A. (2018). O ensino de STEM (Ciência, Tecnologia, engenharia e matemática) no século XXI. Revista Brasileira de Ensino de Ciência e Tecnologia, 11(2), 224-233. http://dx.doi.org/10.3895/rbect.v11n2.8416.

Paulleti, F. \& Catelli, F. (2018). Um estudo de caso: programas computacionais mediando o ensino de isomeria geométrica. Revista Brasileira de Ensino de Ciência e Tecnologia, 11 (1), 250-269. http://dx.doi.org/10.3895/rbect.v11n1.5759.

Paulo-Ferreira, P. R. N., Borges, M. N., \& Delou-Carvalho, C. M. (2018). Produção de materiais didáticos acessíveis para o ensino de química orgânica inclusivo. ARETÉRevista Amazônica de Ensino de Ciências, 11(23), 1-10.

Pereira, B. O. \& Valle, M. G. (2017). O discurso museológico e suas tipologias em um museu de história natural. Revista Ciência \& Educação (Bauru), 23(4), 835-849. https://doi.org/10.1590/1516-731320170040004.

Pugliese-Marcon, R. (2017). O trabalho do professor de Física no ensino médio: um retrato da realidade, da vontade e da necessidade nos âmbitos socioeconômico e metodológico. 
Revista Ciência \& Educação (Bauru), 23 (4), 963-978. http://dx.doi.org/10.1590/1516731320170040006.

Raad-Viana, R., Matos, S. A. \& Coutinho, F. Â. (2018). Levantamento e análise da abordagem ciência, tecnologia e sociedade nas questões de biologia do ENEM 2009 a 2014. Revista Brasileira de Ensino de Ciência e Tecnologia, 11(2), 1-36. http://doi.org/10.3895/rbect.v11n3.5922.

Reis, J. S., Barbosa, A. J., Sousa, A. G., Melo, E. G., Rodrigues-Oliveira, M. A. \& Souza, M. R. (2017). Evolução biológica: Saberes e aceitação de alunos do ensino médio de uma instituição educacional de Rondônia. ARETÉ-Revista Amazônica de Ensino de Ciências, 10(22), 49-60.

Romanowski-Paulin, J. \& Ens, R. T. (2006). As pesquisas denominadas do tipo "estado da arte" em educação. Revista Diálogo Educacional: Pontifícia Universidade Católica do Paraná, 6(19), 37-50.

Scheid, N. M. J. (2018). História da ciência na educação científica e tecnológica: contribuições e desafios. Revista Brasileira de Ensino de Ciência e Tecnologia, 11(2), 443-458. https://doi.org/10.3895/rbect.v11n2.8452.

Trentin, M. A., Rosa-Werner, C. T. \& Silva, M. (2018). Eletrodinâmica no ensino médio: uma sequência didática apoiada nas tecnologias e na experimentação. RENCIMARevista de Ensino de Ciências e Matemática, 9(5), 94-113. https://doi.org/10.26843/rencima.v9i5.1302.

Valadares-Melgaço, J. \& Pernambuco-Almeida, M. M. C. (2018). Criatividade e silêncio: encontros e desencontros entre os saberes tradicionais e o conhecimento científico em um curso de licenciatura indígena na Universidade Federal de Minas Gerais. Revista Ciência \& Educação (Bauru), 24(4), 819-835. https://doi.org/10.1590/1516$\underline{731320180040002 .}$

Autores

Beatriz Grigio Bornia

Acadêmica de Ciências Biológicas da Unespar, Campus Paranavaí. Bolsisita do Programa Institucional de Bolsas de Iniciação em Desenvolvimento Tecnológico e Inovação

(PIBITI). E-mail: biagrigio@ hotmail.com

Marcia Regina Royer

Bióloga, doutora em agronomia. Professora do colegiado de Ciências Biológicas e do Mestrado em Ensino da Universidade Estadual do Paraná-Unespar. Coordenadora do Programa de Pós-graduação, Mestrado em Ensino: Formação Docente Interdisciplinar, da Unespar. E-mail: marciaroyer@yahoo.com.br 